\title{
INFORMING GOOD LIGHTING IN PARKS THROUGH VISITORS' PERCEPTIONS AND EXPERIENCES
}

\author{
Brandi L. Smith ${ }^{1}$, Jeffrey C. Hallo ${ }^{1, *}$ \\ ${ }^{1}$ Clemson University, Clemson, SC 29634, USA
}

Received 08 July 2019, Accepted 30 October 2019

\begin{abstract}
Park visitors' experiences and outdoor lighting are linked, but no studies have investigated visitor preferences for lighting in these locations, nor reasons for such preferences. Visitors' preferences for lighting may help parks regulate and utilize lighting in a way that both protects resources and provides for quality night experiences. Brightness, Correlated Color Temperature (CCT), and context affects human perceptions of lighting. This paper examines these variables and related lighting preferences in settings common to parks: pathways, amphitheaters, and restrooms. Experimental lighting scenarios were setup at Acadia National Park for brightness ranges typical of each setting. CCTs were chosen based on those common for outdoor lighting - 3000K (yellow), 4200K (white), and 6000K (bluewhite). Scenario light fixtures were operated by control boxes that enabled participants to switch between the three CCTs and to adjust brightness. A survey and semi-structure interviews collected data from visitors. Participants preferred $3000 \mathrm{~K}$ at both the restroom and amphitheater, but $4200 \mathrm{~K}$ at the pathway. A $6000 \mathrm{~K} \mathrm{CCT}$ was undesirable for all locations. Visitors' preferred brightness ranged from 1.4 lux on the pathway to 10.5 lux at the restroom. The most frequently cited reasons for these choices were the desire to provide natural nighttime light levels, maintain natural darkness, create a soothing or subtle setting, and to avoid tripping or falling. Many participants indicated having both negative and positive experiences in parks caused by outdoor lighting. Parks must address outdoor lighting if they are to comprehensively manage the nighttime environment and nighttime visitor experiences common in these places.
\end{abstract}

Key words: Protected areas, Lighting, Park Management, Visitor Experience, Natural Darkness, Recreation

\section{Introduction}

Visitors to parks and protected areas (PPAs) extend their outdoor recreation time beyond sunset to include a variety of nighttime activities (Beeco, Hallo, Baldwin, McGuire, 2011; Collison \& Poe, 2013; Smith, 2007; Smith, 2010; Smith \& Hallo, 2013). Some of these activities are light-sensitive (e.g., stargazing), meaning that the quality of experience may decrease as ambient light brightens. Light that impacts an experience or is otherwise unwanted fits the description of light pollution, defined as "any adverse effect of artificial light including, but not limited to, glare, light trespass, skyglow, energy waste, compromised safety and security, and impacts on the nocturnal environment," (IDA \& IES, 2011, p. 36). Techniques to reduce or prevent light pollution have been identified, including replacing or retrofitting problematic light fixtures. Offending lighting in PPAs may be brought in with recreationists, or may be part of the park's infrastructure.

In its most recent (2006) Management Policies, the U.S. National Park Service (NPS) acknowledges outdoor lighting conditions as being closely tied to the visitor experience and states that the parks' natural lightscapes are to be preserved to the greatest extent possible. It mandates that artificial lighting in its parks be limited to those areas in which security, basic human safety, or cultural requirements must be met. These areas include pathways, amphitheaters, and comfort stations (e.g., restrooms, sinks). Despite this awareness that visitor experiences and

* Jeffrey C. Hallo, Tel : +1-864-656-3237

E-mail : jhallo@clemson.edu 
outdoor lighting characteristics are linked, no studies have investigated visitor preferences for outdoor lighting in these locations, nor have reasons for such preferences been examined (Manning, Lawson, Newman, Hallo, Monz, \& Barber, 2018). This lack of understanding may be hindering the ability of PPAs to manage lighting in a way that is most conducive to quality nighttime experiences. Further, the quality of nighttime recreation activities (i.e., the visitor experience) in PPAs may be degraded by lighting that is incompatible with light-sensitive pursuits, such as stargazing.

Outdoor lighting techniques are often chosen based on upfront cost rather than energy efficiency, quality of light output (lessening of glare, increase in useable light), or user preferences (IES \& IDA, 2011; Clark, 2008). Likewise, parks with historical structures often choose fixtures based only on compliance with the historical codes pertaining to the area, while neglecting the "nighttime scene" (NPS, 2007, p. 6). Lighting design may not be fully considered in PPAs because of a lack of knowledge about lighting, including how lighting designs can improve or decrease visibility, the connections between lighting and safety, and potential impacts from lighting (Shi, 2010; Mizon, 2002; Smith, 2007). It is also likely that PPA managers and visitors may not realize that poorly designed lighting fixtures can be retrofitted to reduce light pollution and make a given area more visible to users (Shi, 2010; Smith \& Hallo, 2011).

It should be noted that the involuntary nature of human visual processes implies that the average person does not often consciously consider or understand lighting conditions that enhance or degrade their ability to see (Schiffman, 2000). People are also often not aware of the implications of poor lighting design unless they see the same scene under good lighting conditions to allow for direct comparisons or are otherwise knowledgeable about good lighting practices. This lack of awareness may be at least partially due to poor lighting and light pollution that are part of the "normal" night condition for many people (Kenrick, Goldstein, \& Braver, 2012), producing a degree of habituation to light pollution. Therefore, research that looks to better understand lighting preferences of visitors in PPAs should use an experimental design that allows participants to view lighting conditions first-hand-traditional use of pictures to show conditions are likely inadequate and invalid for the variables under study.

\subsection{Preferences for Brightness and Correlated Color Temperature of Lighting}

Studies have investigated perceptions and preferences of lighting design components, including brightness and correlated color temperature (CCT). Brightness is the psychological product of electromagnetic radiation stimulating the eye. Complete darkness prevents visual sensory input, potentially decreasing the amount of information a person has about their surroundings, whereas the introduction of light increases visual cues available for processing (Schiffman, 2000; Steidle, Werth, \& Hanke, 2011). People may therefore perceive brighter areas as providing better visibility, or acuity, than dimmer areas. To illustrate, in urban settings where study participants felt they could flee from danger if needed, the presence of bright lighting (to find the escape route) was rated to be significantly more important than in instances where the setting did not allow for escape (Blobaum \& Hunecke, 2005; Nasar \& Jones, 1997). Other studies show that pedestrians have rated brighter outdoor lighting as safer and "more interesting" (Boyce, Eklund, Hamilton, \& Bruno, 2000) and as providing more accessibility to information, such as street numbers, than dimmer light (Johansson, Rosen, \& Kuller, 2011). Brightness also affects spatial judgments and psychological distance (Steidle, Werth, \& Hanke, 2011). Specifically, Stamp III and Krishnan (2011) found brighter rooms to be rated as more spacious than darker ones in a controlled laboratory experiment. However, lighting that is too bright can result in physical discomfort to the eye due to over stimulation (Tuaycharoen \& Tregenza, 2005) and can reduce visibility (IDA \& IES, 2011). Izso, Lang, Laufer, Suplicz, and Horvath (2009) found that in a population of senior citizens ( $\mathrm{m}$ age $=71$ years), "strong" lighting (5100 lux) decreased participant accuracy in tasks and was rated as more unpleasant and undesirable than that of lower lux readings (100 lux and 1300 lux). Perceptions of brightness are known to be affected by the type of light used (Rea, Bullough, and Akashi, 2009), the CCT of the light (Knight, 2010), and the height of the light fixture along footpaths (Johansson, Rosen, \& Kuller, 2011).

In addition to brightness, CCT influences perceptions and preferences for lighting. The CTT of emitted light, for example, is important in stating preference for lighting scenarios, evaluating lighting conditions, and visibility. Specifically, the CCT affects perception of safety (Johansson, Rosen, \& Kuller, 2011; Rea, Bullough, \& Akashi, 2009), alertness, and mood (Plitnick, Figueiro, Wood, \& Rea, 2010). Some studies have found that light perceived as white increases feelings of safety, is perceived as more pleasing, and is significantly preferred over yellowish lighting (Knight, 2010; Rea, Bullough, \& Akashi, 2009), the product of High-Pressure Sodium (HPS) bulbs. Yet, HPS bulbs are documented to be least disruptive to nocturnal species behavior and migration and produces less skyglow than light perceived as white (Rich \& Longcore, 2006). 


\subsection{Context of Lighting}

In addition to brightness and CCT, the context of lighting conditions affects human perceptions of - and reactions toward-lighting. For example, perception of and tolerance for glare is affected by how interested a person is in what they are viewing (Tuaycharoen \& Tregenza, 2005). Butler and Biner (1987) found that visual perceptions and preferences for lighting conditions are also influenced by the place a person is in, the task they are attempting, and who they are with. Additionally, the study found that the level of lighting brightness is most important to those preferring either a very dark or a very bright setting as opposed to those with more moderate preferences. Further, darker lighting is preferred by people when alone and brighter lighting is preferred by people in a group setting.

Preferences for lighting and lighting conditions have shown a link to perceived risk of crime or danger, which may be a partial reflection of a human evolutionary-based fear of darkness (Kenrick, Griskevicius, Neuberg, \& Schaller, 2010). However, such perceptions from study participants may be inaccurate as lighting conditions chosen in experiments are not always those that provide for the best vision and may hamper the ability to see and detect threats. Brighter light, for example, may be sought out over a dimmer light in a public setting (Farrington \& Welsh, 2002). Yet, the glare associated with brighter light reduces acuity and obscures subjects within the glare light, including threatening people and dangerous situations. In turn, a person cannot see these threats, increasing their susceptibility to negative outcomes despite the sense of security given by brighter light. This could be made worse by the relatively greater advantage that lighting may provide attackers. Glare and street light CCTs can also prevent motorists from seeing pedestrians or wildlife, creating potentially hazardous situations.

The popularly held belief that brighter light improves safety and controls crime is also often perpetuated by public officials, reinforcing this scientifically unsupported belief. Moreover, some public office reports on public lighting equate "lighting improvement" with increased brightness and "poor lighting" with dim lighting (Clarke, 2008), neglecting consideration of any other lighting characteristics (e.g., CTT, shielding of light source, pole height, ambient brightness). PPA users may transfer these lighting beliefs and preferences with them to their recreation experiences. Likewise, PPA managers may make outdoor lighting decisions based on these same considerations.

Park visitors who venture outdoors during nighttime hours may be concerned about personal safety (e.g., being victimized by crime, encounters with wildlife, tripping or falling, becoming lost), or may be fearful of dark places (Johansson, Rosen, \& Kuller, 2011; Kenrick, Griskevicius, Neuberg, \& Schaller, 2010; Rickard, Scherer \& Newman, 2011). Such concerns may prevent visitors from participating in at least some nighttime experiences. Park managers are also typically concerned with providing safe and secure environments in their parks for both visitors and park personnel (Rickard, et al., 2011; Smith \& Hallo, 2011).

\subsection{Good Lighting Practices}

Findings about perceptions and reactions to lighting, as well as observations about lighting scenarios that result in light pollution, have helped identify lighting techniques and designs that result in more pleasing, sustainable, energy efficient, and natural outdoor nighttime lighting. These lighting techniques include the ways in which lighting is used, such as when a particular light or type of light can be used or how a luminary is shielded to direct light to the intended target while minimizing or preventing light trespass, glare, and sky glow (IDA \& IES, 2011; Mizon, 2002; NPS, 2006; NPS, 2007; Smith, 2007). Given that exposure to light brings about adaptive changes in the eye, it follows that attempts to control nuisance lighting place emphasis on shielding the eye from anthropogenic light, typically referred to as "shielding," or as utilizing "full cut-off" lenses. Because there is no one official lighting policy or set of lighting recommendations for the U.S., this paper utilized the lighting techniques or options prescribed by the IDA \& IES (2011) and the U.S. National Park Service (NPS) Night Sky Team (2007). Examination of these two documents yielded a list of recommended lighting techniques where appropriate, listed in Table 1.

\subsection{Research Purpose and Questions}

Although many studies have addressed lighting brightness and CTT in various contexts, it remains unknown what lighting characteristics (e.g., brightness, CCT) would be considered acceptable in PPAs by nighttime recreationist. Factors that may influence such lighting preferences (e.g., task, location) have also gone unstudied. The present research looks to begin to fill this lack of information. Understanding PPA user preference for lighting may help 
PPAs regulate and utilize lighting in a way that both protects resources and provides for quality night experiences for users. Accordingly, this study seeks to address the following research questions:

1) What is the preferred CCT for three primary park locations (i.e., pathway, amphitheater, comfort station)?

2) What is the preferred brightness of the CCT for each of the three locations?

3) What factors or reasoning led to the lighting choices made?

4) Has outdoor lighting ever influenced participants' experience in a PPA?

Table 1. Good Lighting Techniques or Options to be considered in parks, where appropriate.

Different types of light, light fixtures, or lighting strategies for different zones or areas of the park

Restrictions on times when lights are allowed (or not allowed) to be turned on by visitors or campers (i.e., a lighting curfew)

Restrictions on the types, number, or brightness of lights allowed to be used by visitors

Lights that are shielded to direct light to only intended areas

Lights that are directed downward

Lights that draw attention to or accent something specific (including lights that illustrate phosphorescence)

Light that appears 'soft', 'warm', or 'easy on the eyes'

LED lights

Lights that are set to the minimum necessary brightness

Light that are energy- efficient

Lights that are motion activated

Use of red lights to maintain dark adaptation

\section{Methods}

A team of lighting professionals from MUSCO Lighting Company, headquartered in Oskaloosa, Iowa, were consulted by the researchers and served as the technical experts on this study. MUSCO has evaluated and relit several NPS units in accordance to good lighting practices, including Big Bend National Park and the Washington Monument, and has worked with the NPS Night Sky Team.

\subsection{Study site.}

This study was conducted in Acadia National Park, Maine (ACAD). ACAD is located along the southern coast of Maine, with park headquarters approximately 50 miles $(80 \mathrm{~km})$ southeast of Bangor, Maine and 264 miles (425 km) northwest of Boston, Massachusetts. The park encompasses 47,748 acres (19,323 ha), the majority of which is located on Mt. Desert Island. Its landscape is rocky and mountainous, heavily vegetated, and has dense deciduous forests, along with numerous bodies of water. Ground transportation options in the park include a shuttle bus. Its visitation count in 2018 was 3,537,575 visits, ranking it as the 7th most visited national park (NPS, 2019). Popular recreation activities in the park include birding, camping, hiking, and stargazing.

The park was chosen based on two primary criteria: 1) a substantial level of night visitation and 2) the park's managers expressed interest in better understanding visitors' preferences for nighttime lighting in the park. The experimental design utilized in this study also required that a portion of the selected park's nighttime lighting be temporarily bypassed and use of lighting fixtures designed for this study be installed and used in their place. ACAD management was agreeable to this. MUSCO designed and installed these fixtures to fit the researchers' criteria. A 2day site visit in June 2012 with key park management personnel helped determine that the Blackwoods Campground would be the location of study. 


\subsection{Lighting scenarios.}

The researchers wanted to examine lighting preferences in settings common to PPAs and campground areas. These were a) a pathway, b) an amphitheater, and c) a comfort station (e.g., restrooms and a room with facilities for cleaning camping and cooking equipment). The MUSCO technical team designed the lighting fixtures used in this study in accordance with the research questions and industry standards for typical lux ranges for each of these locations. CCTs were chosen based on those most common for outdoor lighting-3000K (yellow), 4200K (white), and 6000K (bluewhite). However, it should be noted that current debate and guidance, not available at the time of the study, indicates that CCTs in the range of 1900 to $3000 \mathrm{~K}$ might be best for outdoor lighting and related environmental protection (Donatello, Quintero, Caldas, Wolf, Van Tichelen, Van Hoof, Geerken, 2019). The light sources within the fixtures were LEDs. It should be noted that LED light sources can be adjusted to produce a range of CCTs typically associated with incandescent, fluorescent, or high-pressure sodium (HPS) sources. Fixture heights for those located along the walkway were specified to the height (i.e., approximately 48 inches) known to give a functional disbursement range of light for the task of walking along such a pathway. The amphitheater fixture was raised to just below the height of the park's current fixture in this location. Comfort station lighting was placed under the awning of the building, receded from view, adjacent to the park's current lighting.

Fixtures were designed to be operated by control boxes that enabled participants to switch between the three CCTs and to adjust brightness from minimum to maximum lux outputs (i.e., a dimmer dial). Lux values were not labeled on the dials but were marked from " 0 " to " 40 " around the radius of the dial to enable recording of participant responses. It is noted that the validity of participant responses associated with dimmer dial adjustment tasks has been called into question in relation to a sometimes observed stimulus range bias (i.e., participants state a preference for the mid-range brightness) (see Fotios \& Cheal, 2010). However, this method was deemed the most practical for the present research environment.

\subsection{Instrument Development.}

A paper-based questionnaire was developed based on previous research and expert opinion, and the lighting practices in Table 1. It was designed to measure visitor perceptions of nighttime lighting in PPAs. A script was written for use when conducting each participant's lighting evaluation session, including prompts for participant responses to the lighting scenarios and questions to be asked during the terminal semi-structured interview. These questions were guided by the study's research questions and associated literature.

\subsection{Participant Recruitment.}

Participant recruitment occurred in the campsites and evening ranger programs at the amphitheater of the Blackwoods Campground. Visitors who were a) over 18 years of age and b) had spent at least some time in the park after sunset on the current visit were eligible to participate - an overnight stay was not necessary. Every nth visitor was screened for eligibility and asked to participate accordingly.

\subsection{Data collection}

Data collection was conducted onsite for a two-week period at ACAD. Time constraints associated with conducting each experiment session between nightfall (approximately 9:30 pm) and quiet hours (10:30 pm) limited participation to a maximum of six people per night. Upon recruitment, participants were given the questionnaire to complete and then were assigned a time and location to meet the field workers for the lighting scenario evaluation. Prior to data collection, participants were generally exposed to low light levels associated with a national park campground at night, with minimal artificial lights. Also, they were visually acclimated to natural darkness for approximately 10 minutes, during which they participated in other aspects of a broader study, before being exposed to any lighting associated with the study reported here. 


\subsection{Lighting scenario evaluation procedure.}

At the start of data collection each evening, the study lighting was turned on and the existing park lighting in those locations was turned off. Study participants were asked to view the three different CCTs at each of the three lighting locations. For each CCT, participants were instructed to manipulate a dial that controlled the brightness for that CCT diode in the lighting fixture and to indicate when the light brightness became a) too bright, b) too dim, and c) preferred for approaching (amphitheater and comfort station) or traversing (pathway). This procedure produced 27 brightness ratings per participant. CCTs were referred to as colors "A", "B", and "C" to avoid potential biasing effects arising from characterizing the CCT (e.g. "warm," "white," "soft"). Table 2 provides the lux ranges available via the dimmer dial for each CCT at each evaluation station. Participants who felt a condition had not been met for a given scenario (i.e., too bright, too dim, preferred brightness) were instructed to tell the researcher that no setting met the particular condition.3

Table 2. Available lux ranges by location and CCT.

\begin{tabular}{llll}
\hline \multirow{2}{*}{ Location } & CCT & & \\
\cline { 2 - 4 } & $\mathbf{3 0 0 0 K}$ & $\mathbf{4 2 0 0 K}$ & $\mathbf{6 0 0 0 K}$ \\
\hline Pathway & $0.01-11.5$ & $0.01-14.7$ & $0.01-21.6$ \\
Amphitheater & $2.5-13.1$ & $3.1-24.8$ & $4.0-28.4$ \\
Comfort Station & $0.00-39.1$ & $0.00-53.1$ & $0.00-51.7$ \\
\hline
\end{tabular}

Following brightness ratings at each location, participants were asked to state which one of the three CCTs they preferred for the location and which, if any, they found undesirable for the location. A semi-structured short-answer interview was then conducted with each participant upon conclusion of all lighting evaluations to understand the reasoning behind the lighting preferences given during the evaluation sessions. Each location evaluation took an average of 10 minutes to complete, resulting in an average of 30 minutes to complete the entire lighting evaluation. Interviews averaged less than 10 minutes per participant.

\subsection{Analysis}

Descriptive statistics were used to establish a preferred CCT for each lighting evaluation location. Lighting evaluation responses for the preferred CCT at each location was plotted against lux values to illustrate a) the range of acceptable brightness, b) the preferred brightness, and c) the minimum acceptable brightness. Data resulting from open-ended survey questions and interviews were coded using basic qualitative analysis techniques. Frequencies of identified categories resulting from the coding were then tabulated.

\section{Results}

A total of 66 people took part in this study. The average participant age was 41.4 years, ranging from 18 to 63 years of age. Males made up 56.1\% of the sample and $92.5 \%$ of the sample reported being of Caucasian ethnicity. Participants' lighting evaluation responses for the task of approaching, traversing, and departing evaluation stations are summarized in Table 3.

\subsection{Preferred CCT.}

CCT preference varied by location. Participants preferred 3000K, the 'warmest' choice available to them, at both the comfort station and the amphitheater, but preferred 4200K for the pathway. The most undesirable CCT was $6000 \mathrm{~K}$ for all locations. 
Table 3. Lighting evaluation results.

\begin{tabular}{|c|c|c|c|c|}
\hline \multirow{2}{*}{ Location } & \multirow{2}{*}{ Variable } & \multicolumn{3}{|l|}{ CCT } \\
\hline & & $3000 \mathrm{~K}$ & $4200 K$ & $6000 \mathrm{~K}$ \\
\hline \multicolumn{5}{|l|}{ Pathway } \\
\hline \multicolumn{5}{|c|}{ Condition Ratings (lux) } \\
\hline & Too Bright & $3.2(2.7)$ & $4.8(4.4)$ & $5.1(5.4)$ \\
\hline & Preferred & $1.2(1.4)$ & $1.4(1.4)$ & $1.2(1.3)$ \\
\hline & Too Dim & $0.5(1.0)$ & $0.6(0.6)$ & $0.5(0.5)$ \\
\hline & \multicolumn{4}{|l|}{ CCT Desirability } \\
\hline & $\%$ Preferred & $37.9 \%$ & $43.9 \%$ & $10.6 \%$ \\
\hline & $\%$ Undesirable & $19.7 \%$ & $10.6 \%$ & $50.0 \%$ \\
\hline \multicolumn{5}{|c|}{ Amphitheater } \\
\hline & \multicolumn{4}{|l|}{ Condition Ratings (lux) } \\
\hline & Too Bright & $9.6(2.3)$ & $14.4(5.1)$ & $14.3(7.6)$ \\
\hline & Preferred & $7.2(3.3)$ & $8.3(4.0)$ & $8.0(4.4)$ \\
\hline & Too Dim & $3.8(1.9)$ & $5.0(2.5)$ & $5.4(3.1)$ \\
\hline & CCT Desirability & & & \\
\hline & $\%$ Preferred & $57.6 \%$ & $24.2 \%$ & $10.6 \%$ \\
\hline & $\%$ Undesirable & $15.2 \%$ & $10.6 \%$ & $56.1 \%$ \\
\hline \multicolumn{5}{|c|}{ Comfort Station } \\
\hline & \multicolumn{4}{|l|}{ Condition Ratings (lux) } \\
\hline & Too Bright & $20.7(12.6)$ & $25.5(17.8)$ & $21.4(15.7)$ \\
\hline & Preferred & $10.5(9.9)$ & $9.2(11.0)$ & $7.8(8.8)$ \\
\hline & Too Dim & $4.2(5.0)$ & $2.8(4.8)$ & $4.4(9.2)$ \\
\hline & \multicolumn{4}{|l|}{ CCT Desirability } \\
\hline & $\%$ Preferred & $50.0 \%$ & $22.7 \%$ & $13.6 \%$ \\
\hline & $\%$ Undesirable & $21.2 \%$ & $12.1 \%$ & $47.0 \%$ \\
\hline
\end{tabular}

Note: Mean (Standard Deviation)

$\mathrm{N}=66$

\subsection{Preferred brightness.}

Perceptions of brightness varied according to the location of the evaluation. The CCT also affected perceptions of brightness at each location. The condition of "too bright" received the largest range of lux output values across locations (Table 3). However, as shown in Table 4, not all participants found a point of brightness that they deemed to be "too bright" or "too dim." The amphitheater had the highest number of participants who felt that there was neither a condition that was too bright nor too dim.

Table 4. Frequency of participants indicating the lighting evaluation condition did not exist.

\begin{tabular}{lllll}
\hline \multirow{2}{*}{ Location } & Variable & CCT & & \\
\cline { 3 - 5 } Pathway & 3000K & $\mathbf{4 2 0 0 K}$ & $\mathbf{6 0 0 0 K}$ \\
\cline { 3 - 4 } Amphitheater & Too Bright & 1 & 2 & 1 \\
& Too Dim & 5 & 9 & 6 \\
Comfort Station & Too Bright & 23 & 4 & 3 \\
& Too Dim & 9 & 15 & 17 \\
& & & & 3 \\
& Too Bright & 10 & 3 & 3 \\
\hline
\end{tabular}


Note: $\mathrm{N}=66$

Figure 1 depicts brightness ratings for the most preferred CCT for each of the three lighting evaluation locations, illustrating the range of acceptable brightness conditions for each. Figures 2 through 4 show each location lit in the overall preferred CCT for the location with brightness adjusted to the mid-point of the available lux range of the preferred CCT.

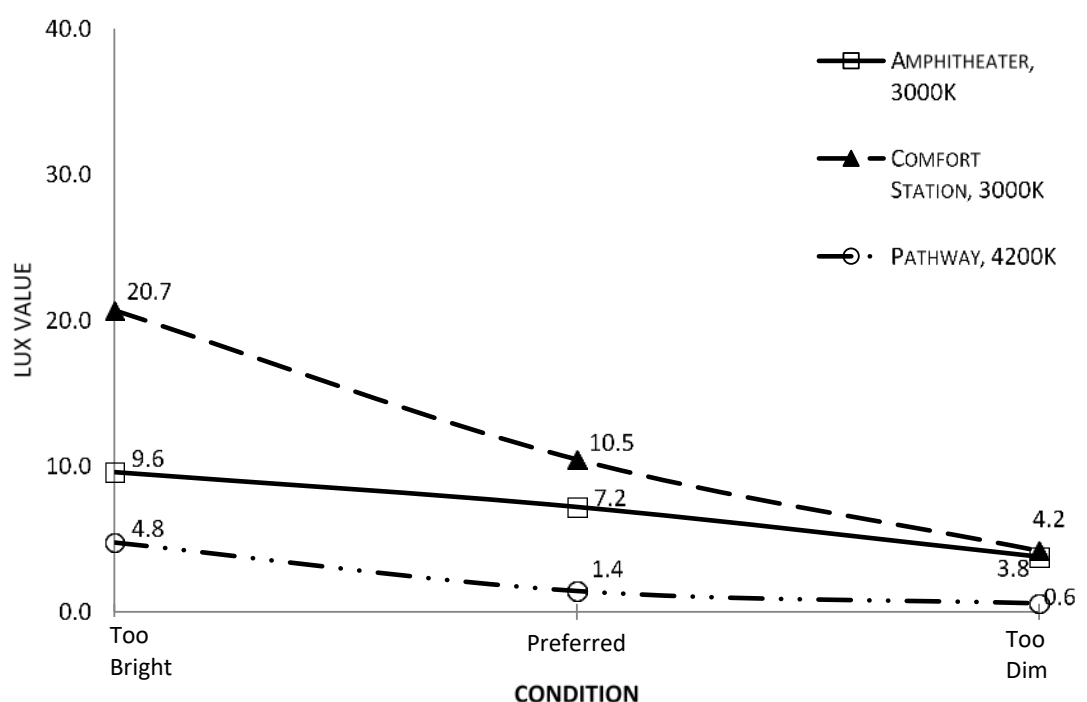

Figure 1. Mean lux values for preferred CTTs. Mean lux values for the preferred CTT for each of the three lighting locations. The YAxis represents the full range of available lux values for the preferred CTT for each location (Amphitheater: 2.5-13.1 lux; Comfort station: 0.0-39.1 lux; Pathway: 0.01-14.7 lux).

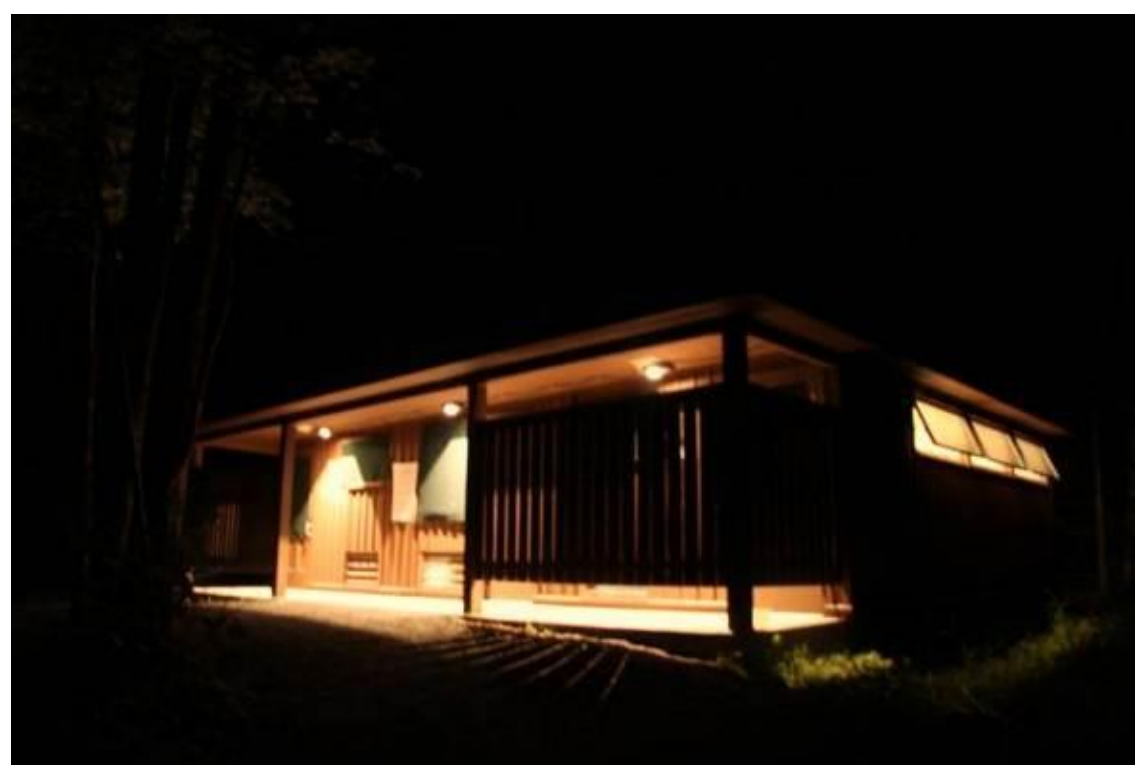

Figure 2. The comfort station at mid-lux range (23 lux) of preferred CCT (3000K), from vantage point of participants. 


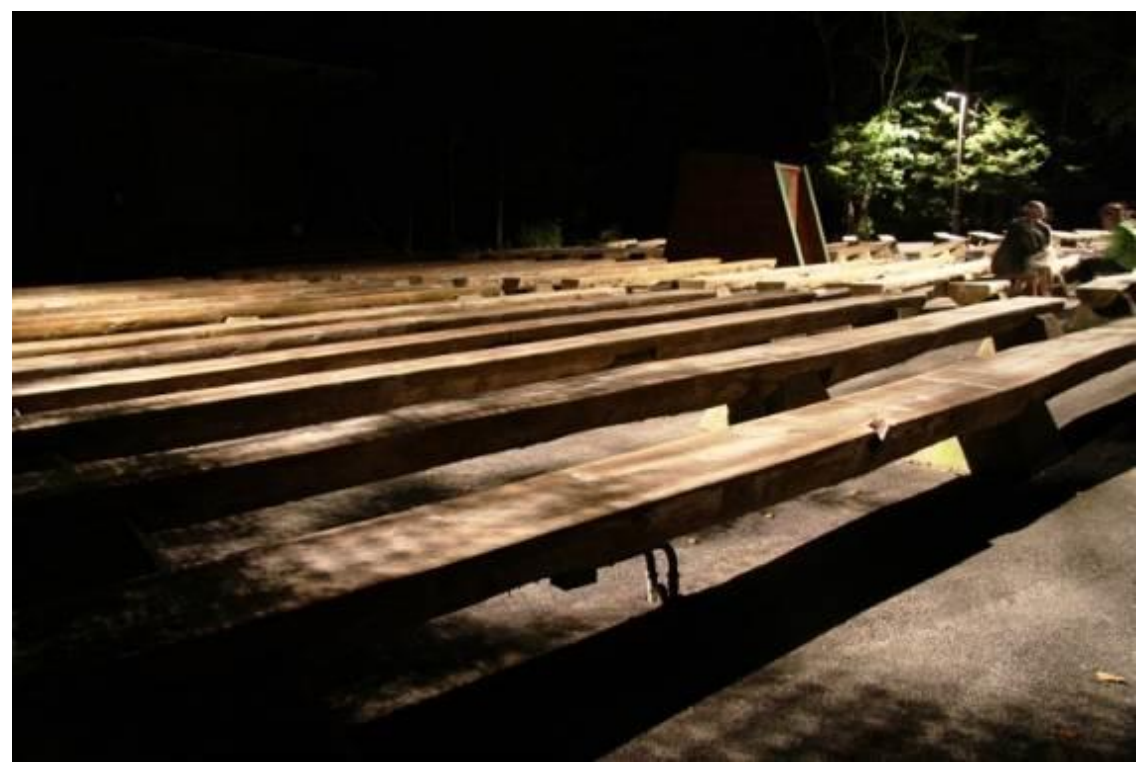

Figure 3. Amphitheater at mid-lux range (7.8 lux) of preferred CCT (3000K), from vantage point of participants.

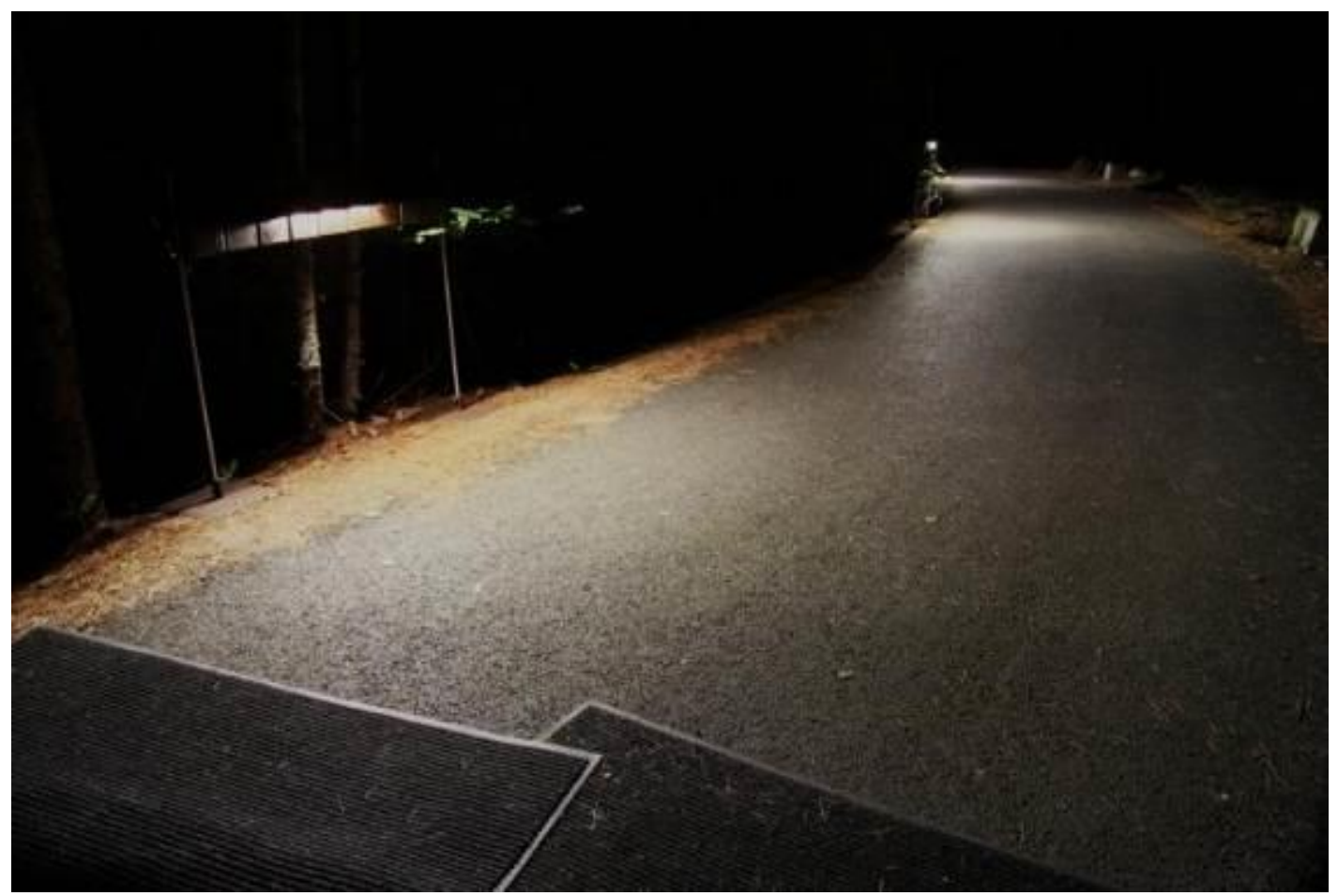

Figure 4. Pathway at mid-lux range (7.4 lux) of preferred CCT (4200K), from vantage point of participants.

\subsection{Reasoning for brightness choices.}

Participants were asked the question: "What factors did you consider, or were you influenced by, when making your choices for brightness?" The most frequently cited reason for choices made regarding brightness was the desire to maintain natural nighttime brightness (i.e., a desire for darkness). Participants next most frequently said their 
choices were based on a dislike of light that was harsh, bothersome, or uncomfortable to their eyes. Responses are summarized in Table 5. Representative participant statements explaining these codes included:

"I want darkness. Bright lights seem too city-like. I come here for darkness and quiet." "Think about being

in a national park. You don't want much light interfering. It's different from when it is dim in a city."

Table 5. Explanations for lighting evaluation brightness choices.

\begin{tabular}{lc}
\hline Code & Frequency \\
\hline Maintain natural night/ want darkness & 22 \\
Harsh/ bothersome/ uncomfortable & 19 \\
Safety & 12 \\
Sense of place & 11 \\
Task/ usability & 9 \\
Seeing/ night vision & 7 \\
Night Recreation/ night resources & 4 \\
CCT & 3 \\
Aesthetics & 2 \\
Sharpness/ clarity & 2 \\
Subtle & 2 \\
Way-finding & 2 \\
Energy efficiency & 1 \\
\hline
\end{tabular}

Note: $\mathrm{N}=66$.

\subsection{Reasoning for CCT preferences.}

Participants were asked the question: "What factors did you consider, or were you influenced by, when making your choices for color?" Participants most frequently said their CCT ratings were related to a desire for a CCT that was soothing or subtle (i.e., non-obtrusive). A CCT's "sense of place" (i.e., felt appropriate for a park campground area) was the second most frequently stated explanation for CCT desirability. Participants often gave the same reasoning for both brightness and CCT. Table 6 summarizes codes assigned to explain CCT choice responses. Representative participant statements explaining some of these codes included

'Color ' $a$ ' is emotive, good for groups, but color ' c' gets your attention- good for a single speaker getting audience attention. I prefer softness in the colors-harsh is least is preferred, is more industrial."

"I like natural colors. Color 'c' is frightening;" "I like 'C' for less glare. 'B' is like being under fluorescents,

like at school. I don't like warm shades as much, prefer blue."

"Color [of "b"] blended better, it looked like starlight instead of the artificial yellow look." 
Table 6. Explanations for lighting evaluation CCT choices.

\begin{tabular}{lc}
\hline Code & Frequency \\
\hline Soothing/ subtle & 29 \\
Sense of place & 16 \\
Temperature- warmth & 12 \\
Natural & 10 \\
Task/usability & 9 \\
Emotion/ mood elicitation & 5 \\
Unable to explain & 4 \\
Aesthetics & 3 \\
Clean & 2 \\
Temperature- cool & 2 \\
Energy efficiency & 2 \\
Safety & 2 \\
\hline
\end{tabular}

Note: $\mathrm{N}=66$

\subsection{Desired PPA lighting characteristics.}

Participants were asked the question "What do you think about when you view lighting in a park setting? What do you like? What do you not like?" Participants indicated most often that they wanted PPAs to maintain natural darkness. When lighting is needed in park settings, study participants reported preferring it to be the minimum needed for the context, or for safety, and for it to be subtle, or 'barely noticeable' against the natural backdrop. Response code frequencies are given in Table 7. Participant statements about safety as a concern in ACAD included:

"I don't want huge stadium lights—I want to see important stuff lit up."

"I like to see where I'm going, but don't want to be bothered with light in my face."

"There shouldn't be any bright light shining into campsites. Use light for way-finding locations, but I use my own light to get there - I want to maximize my night vision."

Table 7. Lighting characteristics favored by participants for park settings.

\begin{tabular}{ll}
\hline Code & Frequency \\
\hline Keep natural brightness/ darkness & 21 \\
Minimum needed for task/ purpose & 18 \\
Minimum needed for safety & 14 \\
Subtle/ non-obtrusive & 12 \\
Light that shines only where intended & 11 \\
Shielded light & 9 \\
No park lights/ use own light-source & 7 \\
Unlit camping areas (including lack of light trespass) & 5 \\
See where going & 5 \\
Sense of place & 4 \\
Way-finding/ beacon & 4 \\
No response & 3 \\
Downward directed light & 3 \\
CCT- warm, firelight-like & 3 \\
Light bulbs that are hidden from view & 2 \\
Fixtures that are low to the ground & 2 \\
\hline
\end{tabular}

Note: $\mathrm{N}=66$ 


\subsection{Lighting and concern for safety.}

Participants were asked the question: "Do you think about safety in regard to lighting in the park-Tripping/falling? Animals/wildlife? Crime?" Participants indicated they were most concerned about tripping or falling after dark in relation to safety (Table 8). Very few reported concerns of threats from wildlife or crime. Participant statements about safety as a concern in ACAD included:

"Yes, to tripping and falling, and wildlife. No, to crime-Everyone leaves each other alone here."

"Tripping and falling mostly. Animals—not worried. Crime-No, not in a national park."

"No, we bring flashlights. Why do you need any light in a park?"

Table 8. Participant concern about nighttime safety (i.e., tripping/ falling, wildlife, crime, other).

\begin{tabular}{ll}
\hline Factor & Frequency \\
\hline Tripping only & 27 \\
No concern & 22 \\
Tripping, animals, and crime & 6 \\
Tripping and animals (not crime) & 6 \\
Animals only & 1 \\
Tripping and crime (not animals) & 1 \\
No response & 3 \\
Other & 2 \\
Crime only & 0 \\
Animals and crime only (not tripping/ falling) & 0 \\
\hline Note. N=66
\end{tabular}

Note. $\mathrm{N}=66$

\subsection{Participant experiences with PPA lighting.}

Participants were asked the questions: "Have you ever had your experience in a park negatively or positively affected by outdoor lighting? Please describe it." A majority of participants $(n=36)$ indicated having had a negative experience in a PPA caused by outdoor lighting, and nearly as many had had positive experiences $(n=33)$. These experiences were not limited to Acadia National Park. Responses are summarized in Table 9. Representative statements include:

Positive "Yes. When you wake up in the middle of the night, you need to know where the bathroom is-the

light shows you where they are."

Positive "Yes—at national monuments. Well-lit at night, attractive and safe feeling."

Negative "Monument Valley-overly bright visitor center parking lot. Night cannot be enhanced, there needs to be a sense of place. The less light, the better. If you're nervous about the park, you shouldn't be there. You cannot enhance nature. Light for safety only." 
"Negative-yes. Here in ACAD, being near the bathroom on A-Loop, the lights were too bright and flashlights in our eyes [from people going to the bathhouse]. And during "Stars over Sandbeach," flashlights were on and off, and that disturbed our night vision."

Table 9. Participant frequency for PPA experiences ever being either positively or negatively influenced by lighting

\begin{tabular}{ll}
\hline Factor & Frequency \\
\hline Both positive and negative & 24 \\
Neither & 20 \\
Negative only & 13 \\
Positive only & 9 \\
\hline Note. N=66 &
\end{tabular}

\section{Discussion}

The purpose of this study was to better understand nighttime recreationists' lighting preferences in PPAs by measuring their reactions to an array of in-person lighting conditions at three commonly used locations within an NPS campground area. Overall, this study showed that both brightness and CCT of outdoor lighting in PPAs can impact visitors' nighttime experiences and that those visitors have preferences and expectations for lighting in PPAs. Therefore, parks looking to provide for quality instances of nighttime recreation must address their outdoor lighting characteristics if they are to comprehensively manage the nighttime environment for the visitor experience.

Participants were better able to explain preferences for brightness than for CCT, although many had the same explanations for both. This better articulation for the concept of brightness suggests it is more intuitive and overt than is "color" of light. It is suspected that without the experimental, in-person evaluation of the lighting conditions participants would not have been able to render an accurate mental picture of the different CCTs to state preferences or reasoning. This highlights the importance of first-hand viewing of lighting conditions when asking PPA visitors to comment on them. It is acknowledged that lighting experiments such as the one carried out in this study are elaborate undertakings that may not be practical to implement at all NPS units, or other PPAs. Smaller-scaled staging of lighting conditions in PPAs may be viable alternates, as might other approaches, and should be the subject of inquiry.

\subsection{Brightness.}

Participants were instructed to make choices regarding brightness for the same task (i.e., approaching, traversing, departing the area) at each evaluation location (i.e., pathway, amphitheater, comfort station). Brightness ratings fluctuated for each condition (i.e., too bright, preferred, too dim) and for each CCT, indicating that task is not the sole driver in light brightness preferences. Context - in the form of a park location-clearly influenced perceptions of brightness. When asked what factors they considered when making brightness judgments, participants most often reported wanting to maintain natural night conditions and avoid lights so bright that they were harsh, bothersome, or uncomfortable. However, the average response for "too bright" at the comfort station did not occur until 20.7 lux in the preferred CCT of $3000 \mathrm{~K}$ - much brighter than natural conditions would be. Still, this was nearly half as dim as the maximum brightness possible for $3000 \mathrm{~K}$ at this location. Ratings for "too bright" at the other two locations were much dimmer.

These seemingly incongruent responses may be due to several factors. First, the experimental lighting being rated used good lighting practices. Thus, there was little to no light trespass from the location of the lighting fixture and the evaluation stations, regardless of the selected brightness. These characteristics may have made the brightness feel more natural (acceptable) than it would have had the fixtures not been shielded and pointed downward, or if glare had been present. 
Secondly, the brightest preference and range of acceptable conditions were obtained at the comfort station. Although participants were to consider the task of walking at each location, personal subjective norms about appropriate lighting for bathrooms may have been triggered. That is, there may have been a bias to prefer the area to be brighter around the bathrooms due to belief that the location may be more prone to crime or danger than the others. Several respondents alluded to this in later open-ended responses when discussing concern for safety in relation to park lighting.

Third, several participants mentioned task being important in the choices they made for brightness. This again suggests that although participants were instructed to consider the task of walking when making their choices, they may have considered other additional tasks likely to take place in the evaluation station. At the comfort station, this would support previous findings that brighter lighting is preferred for tasks requiring better visual acuity (e.g., cleaning camping equipment, reading bathroom signs), although previous findings regarding acuity also show $4200 \mathrm{~K}$ to produce better acuity than the $3000 \mathrm{~K}$ that was selected at the comfort station (Navvab, 2001, 2002).

Fourth, anchor brightness refers to the level of illumination participants see a location to have just prior to engaging in their brightness adjustment task (Logadottir, et al., 2011). Although anchor brightness was not a variable in this study, observed findings suggest it may have been a factor in brightness adjustments. Specifically, of the three evaluation stations, the comfort station was the only station that had a non-zero lux value upon participant arrival. This may have influenced brightness ratings, accounting for some portion of the brighter evaluations obtained at the comfort station.

Findings in this study did not demonstrate the often observed stimulus range bias, where participants choose the mid-brightness point as their preferred brightness (see Fotios \& Cheal, 2010). As suggested by participants' explanations for brightness evaluations, this is likely due to participants having specific expectations for the sites' illumination and associated tasks. Moreover, study participants were foremost park visitors who were recreating in the park at night. They had no prior knowledge that the study was being conducted and were recruited due to, and during, their role as nighttime recreationists. This is atypical of many experimental design studies in which participants are recruited for participation on criteria unrelated to the task or setting they will evaluate. Moreover, they typically only go to the study site to participate in the trial-with no other motivation for going to the location. This suggests that stimulus range bias may be related to study site or task expectations regarding the stimulus, which may be further affected by the strength of personal norms for lighting in a location.

Relevancy of setting and task in relation to the stimulus seems to play a role in range selection. The available range of brightness may not influence preference selection as much if participants have a true preference for the stimulus based on the study context or who feel vested in the outcome. Cases in which no true preference exists for the stimulus in the setting or where no relevance is felt for the task may simply revert to the average of the available range.

An additional difference between the present study and those that have observed stimulus range bias is the condition(s) participants were asked to identify. Specifically, the present study asked participants to identify preferred brightness, but also to identify the point at which illumination became too bright and the point at which illumination became too dim. Participants saw the full range of illumination and the dial was returned to its "0" point, from which participants were asked to perform their adjustment task. At least some studies where stimulus range bias has been observed only asked participants to identify their preferred brightness. This suggests that participants who must consider the range of brightness to a greater extent may be more discriminate in identifying the preferred condition regardless of the available range.

Future investigation into lighting preferences, including those on stimulus range bias, should address the relevance of the condition and stimulus to the participants, as well as the effect of requiring participants to examine the available range of brightness to a greater degree (i.e., identify conditions in addition to the preferred condition).

\subsection{CCT preferences.}

Study participants indicated they preferred a light's CCT to be natural, provide a sense of place, and be appropriate in the outdoors. This was reflected in the overall preference of $3000 \mathrm{~K}$ in both the comfort station and the amphitheater, which was likened to campfire light. However, $4200 \mathrm{~K}$ was preferred for the walkway, with explanations alluding to better acuity under that CCT as compared to $3000 \mathrm{~K}$ or $6000 \mathrm{~K}$, with descriptions such as "cleaner."

This finding is contradictory to previous research that has shown $4200 \mathrm{~K}$ to be preferred over $3000 \mathrm{~K}$. However, the previously observed preferences for $4200 \mathrm{~K}$ have been traced back to CCT producing increased feelings of safety over $3000 \mathrm{~K}$ and also rendering better acuity. In the present study, participants reported low concern for safety, except 
in the context of tripping or falling. This seems to partially explain the greater preference for $3000 \mathrm{~K}$. The walkway was the exception to this, and was the one place $4200 \mathrm{~K}$ was preferred in this study. Given that the greatest concern for safety was tripping or falling, it is logical that participants preferred $4200 \mathrm{~K}$ for better acuity related to safety. In the amphitheater and comfort station, the appropriateness of the CCT for the setting seems to explain some of the preference for $3000 \mathrm{~K}$ in these locations. It should be noted that $3000 \mathrm{~K}$ was the lowest (i.e., warmest) CCT choice available to respondents. This minimum CCT is a limitation that should be changed in future studies to explore preferences for CCTs at $1900 \mathrm{~K}$ and $2700 \mathrm{~K}$, which are now being debated as more appropriate for outdoor settings such as parks and protected areas.

\subsection{Concern for safety.}

That participants were most concerned about tripping or falling as opposed to crime suggests that PPA visitors do not maintain the same degree of concern for safety as they do in other locations at nighttime. Moreover, these findings imply that causes for concern for safety are place and context specific. For PPAs, safety concerns may not be stable from one internal location to the next as demonstrated by the differing lighting condition ratings between evaluation locations in this study. Several study participants specifically indicated a desire for brighter lighting at the comfort station than the other two locations out of a heightened concern for safety.

The concern for safety in relation to lighting preferences in this study may be biased by the characteristics of the campground and of ACAD itself. First, ACAD lacks predatory species (e.g., bears, mountain lions). Visitors at PPAs containing populations of these animals may have a much greater concern for their safety during nighttime hours. Second, Blackwoods Campground is relatively large and lacks any isolated campsites. This adjacency of others may help foster a sense of security that may be lacking if fewer people were around. Conversely, some participants said it was the potential of dangerous others that led them to want the brightness they specified, especially at the comfort station. Third, the indicated feelings of safety in regard to crime may have been influenced by the contact with park rangers at the campground check-in kiosk and knowing that law enforcement rangers were present in the park. Changes in any of these three factors in other parks could translate into different lighting preferences or concerns for safety.

\subsection{Preferred PPA lighting characteristics.}

Participants' preferred lighting characteristics for PPAs were largely consistent with their responses elsewhere in the study, stating an overall desire for natural nighttime conditions expected in an NPS campground area (e.g., subtle, sense of place, natural). Comments about lighting being used as a beacon to find restrooms illustrated a way that light could be used to enhance the nighttime experience, providing that such light was minimal and unobtrusive. Participants indicated specific dislike for lights that illuminated tent areas, especially those being emitted from comfort stations. This information may be useful to PPA planners who wish to provide quality experiences for visitors.

\subsection{Participant experiences with PPA lighting.}

Participants' accounts of their park experiences being impacted or enhanced by outdoor lighting suggest that both poor and good lighting practices in PPAs are wide-spread. Moreover, responses to these questions emphasize that nighttime lighting characteristics do affect visitors' nighttime experiences in PPAs, even those that do not provide for overnight camping or lodging. For example, several participants mentioned monument viewing in Washington, D.C. as times when lighting had enhanced a nighttime park experience. At least in the case of the monuments located in Washington, D.C., lodging does not exist in the park unit, yet nighttime lighting plays an important role in those units' ability to allow the public to experience and enjoy the monuments.

\section{Conclusions}

Findings of the present study provided a deeper understanding of lighting preferences among nighttime recreationists in one NPS unit—Acadia National Park—and are likely able to inform visitor-preferred lighting 
characteristics at other PPAs. Preferences for brightness and lighting CCTs at three different evaluation locations, coupled with participants' explanations of responses indicated that preservation of natural nighttime conditions (i.e., darkness) is a priority to nighttime recreationists in this study. When lighting is necessary, it is preferred to be of minimum brightness and rendered in a CCT that "blends" with the natural outdoor setting, rather than being reminiscent of industrial or city-like lights. Concern for safety, other than tripping or falling, had little bearing on preferred lighting. However, ability to engage in quality instances of nighttime recreation, such as stargazing, hiking on dark trails, and experiencing darkness, were major considerations for participants' evaluations. This demonstrates the importance of natural nighttime conditions and good lighting practices in PPAs. Degradation of nighttime's natural darkness in such places translates to degraded quality of experiences for nighttime visitors. Use of good lighting practices can maintain and protect the integrity of the nighttime experience for both current and future generations of visitors.

\section{Acknowledgements}

Funding for this research was provided as part of the Good Lighting Fellowship sponsored by Joe Crookham and Jeanie Bieri of Musco Lighting.

\section{References}

[1] Beeco, A., Hallo, J., Baldwin, B., McGuire, F. (2011). The guided night experience in parks and protected areas. Journal of Park and Recreation Administration, 29(4), 72-88.

[2] Blobaum, A., \& Hunecke, M. (2005). Perceived danger in urban public space: The impacts of physical features and personal factors. Environment and Behavior, 37, 465- 483.

[3] Boyce, P. R., Eklund, N.H., Hamilton, B.J., \& Bruno, L.D. (2000). Perceptions of safety at night in different lighting conditions. Lighting Research Technology, 32, 79-91.

[4] Butler, D. L., \& Biner, P. M. (1987). Preferred lighting levels: Variability among settings, behaviors, and individuals. Environment and Behavior, 19, 695-721.

[5] Clark, B. A. (2008). A rationale for the mandatory limitation of outdoor lighting. Melbourne, Australia: Astronomical Society of Victoria Inc. Retrieved from http://asv.org.au/light-pollution.php

[6] Collison, F. \& Poe, K. (2013). “Astronomical Tourism”: The astronomy and dark sky program at Bryce Canyon National Park. Tourism Management Perspectives, 7, 1-15.

[7] Donatello, S., Quintero R. R., Caldas, M.G., Wolf, O., Van Tichelen, P., Van Hoof, V. \& Hoof, Geerken, T. (2019). Revision of the EU Green Public Procurement Criteria for Road Lighting and traffic signals. Luxembourg: Publications Office of the European Union.

[8] Farrington, D., \& Welsh, B. (2002). Improved street lighting and crime prevention. Justice Quarterly, 19(2), 313- 342 . 
[9] Fotios, S., Cheal, C., \& Boyce, P. R. (2005). Light source spectrum, brightness perception and visual performance in pedestrian environments: A review. Lighting Res. Technol., 37(4), 271-294.

[10]Fotios, S., \& Cheal, C. (2010). Stimulus range bias explains the outcome of preferred-illuminance adjustments. Lighting Res. Technol., 42(9), 433-447.

[11] International Dark-sky Association (IDA) \& Illuminating Engineering Society (IES), (2011). Joint IDA- IES model lighting ordinance (MLO) with user's guide. Retrieved from http://www.ies.org/PDF/MLO/MLO_FINAL_June2011.pdf

[12]Izso, L., Lang, E., Laufer, L., Suplicz, S., \& Horvath, A. (2009). Psychophysiological, performance and subjective correlates of different lighting conditions. Lighting Research Technology, 41, 349-360.

[13] Johansson, M., Rosen, M., \& Kuller, R. (2011). Individual factors influencing the assessment of the outdoor lighting of an urban footpath. Lighting Research Technology, 43, 31-43.

[14] Kenrick, D. T., Goldstein, N. J., \& Braver, S. L. (Eds.). (2012). Six degrees of social influence: Science, application, and the psychology of Robert Cialdini. New York, NY: Oxford University Press.

[15] Kenrick, D. T., Griskevicius, V., Neuberg, S. L., \& Schaller, M. (2010). Renovating the pyramid of needs: Contemporary extensions built upon ancient foundations. Perspectives on Psychological Science, 5(3), 292314.

[16] Knight, C. (2010). Field surveys of the effect of lamp spectrum on the perception of safety and comfort at night. Lighting Research Technology, 42, 313-329.

[17]Logadottir, A., Christoffersen, J., \& Fotios, S.A. (2011). Investigating the use of an adjustment task to set the preferred illuminance in a workplace environment. Lighting Research Technology, 43, 403-422.

[18] Manning, R., Lawson, S., Newman, P., Hallo, J., Monz, C., \& Barber, J. (2018). Natural Quiet, Natural Darkness: Managing Noise and Light in the National Parks. Lebanon, NH: University Press of New England.

[19] Mizon, B. (2002). Light pollution: responses and remedies; Patrick Moore's Practical Astronomy Series. London: Springer.

[20] National Park Service (1997). The visitor experience and resource protection (VERP) framework: a handbook for planners and managers. Denver, CO: U.S. Department of the Interior, National Park Service, Denver Service Center. 
B.L.Smith \& J. C. Hallo/International Journal of Sustainable Lighting IJSL (2019) 99-117

[21] National Park Service (2006). Management policies 2006. Denver, CO: U.S. Department of the Interior. Retrieved from http://www.nps.gov/policy/mp2006.pdf

[22] National Park Service (2007). Interim Outdoor Lighting Guidelines (DRAFT), Developed by the Night Sky Team, Version 1.0. $\quad$ Retrieved from http://www.nps.gov/nabr/naturescience/ upload/NPSInterimOutdoorLightingGuidelinesDraft.pdf

[23] National Park Service User Statistics (2019). Report created at https://irma.nps.gov/Stats/

[24] Navvab, M. (2001). A comparison of visual performance under high and low color temperature fluorescent lamps. Journal of the Illuminating Engineering Society, 30(2), 170-175.

[25] Navvab, M. (2002). Visual acuity depends on the color temperature of the surround lighting. Journal of the Illuminating Engineering Society, 31(1), 70-84.

[26]Plitnick, B., Figueiro, M. G., Wood, B., \& Rea, M. S. (2010). The effects of red and blue light on alertness and mood at night. Lighting Research Technology,42, 449-458.

[27] Rea, M. S., Bullough, J. D., \& Akashi, Y. (2009) Several views of metal halide and high-pressure sodium lighting for outdoor applications. Lighting Research Technology, 41, 297-320.

[28] Rich, C., \& Longcore, T. (Eds.). (2006). Ecological consequences of artificial night lighting. Washington, D.C.: Island Press.

[29] Rickard, L. N; Scherer, C.W. \& Newman, S.B. (2011): Exploring attribution of responsibility for visitor safety in a US national park, Health, Risk \& Society, 13(6), 527-545

[30] Schiffman, H. R. (2000). Sensation and perception: An integrated approach (5th ed.). New York, NY: John Wiley \& Sons, Inc.

[31] Schroeder, H. \& Anderson, L. (1984) Perceptions of personal safety in urban recreation sites. Journal of Leisure Research, 2, 178-194.

[32] Shi, J. (2010). Reducing artificial nighttime light pollution and its impacts. Retrieved from http://www.trianglealumni.org/mcrol/EPA-NNEMS_Light_Pollution_Final.pdf

[33] Smith, B. (2007). Grassroots policy prescription: A case study in light pollution and night sky preservation and natural resource policy making (master's thesis). Retrieved from https://www.mhsl.uab.edu/dt/2007m/smith.pdf 
[34] Smith, B. (2010). Dark park potential: Analysis of prevalence and possibilities of night recreation opportunities in state and national park units. Paper presented at The International Symposium on Society and Resource Management, Corpus Christi, TX.

[35] Smith, B., \& Hallo, J. (2011). 2011 Survey on NPS Use and Status of Night Resources. Unpublished report. Clemson University.

[36] Smith, B., \& Hallo, J. (2013). A system-wide assessment of night resources and night recreation in the U.S. national parks: A case for expanded definitions. Park Science, 29(2), 54-59.

[37] Stamps III, \& Krishnan, V. (2011). Spaciousness and boundary roughness. Environment and Behavior, 38, 841- 872. doi 10.1177/0013916506288052

[38] Steidle, A., Werth, L., \& Hanke, E. (2011). You can’t see much in the dark: Darkness affects construal level and psychological distance. Social Psychology, 42(3), 174- 184. doi: 10.1027/1864-9335/a000061

[39] Tuaycharoen, N., \& Tregenza, P. R. (2005). Discomfort glare from interesting images. Lighting Research Technology, 37 (4), 329-341. 